\title{
Soil Moisture Characteristics of a Typical Slope in the Watershed of the Loess Plateau for Gully Land Consolidation Project
}

\author{
Yulin Shan ${ }^{1,2}$, Jiancang Xie ${ }^{1 *}, \mathrm{Na}$ Lei $^{2}$ and Qiguang Dong ${ }^{2}$ \\ ${ }^{1}$ Key Laboratory of Eco-hydraulic Engineering in Northwest Dry Area of Shaanxi Province, Xi'an University of Technology, 710048, \\ Xi'an, China \\ ${ }^{2}$ Shaanxi Provincial Land Engineering Construction Group Co., Ltd., Xi’an 710075, China
}

\begin{abstract}
To clarify the characteristics of soil moisture in the slope of watershed of the gully land consolidation watershed, and to further guide the implementation of the gully land consolidation project and vegetation restoration in this area, this study selected a typical slope of gully land consolidation watershed as the research object. The soil moisture of different slope positions was monitored and analyzed, and its temporal stability was analyzed. The results showed that: 1) The average soil moisture of different slope positions increased with the increase of soil depth, and the variability showed an increasing-decreasingincreasing trend, and the variability was the smallest at about $70 \mathrm{~cm}$ from the surface with weak variability, and the soil moisture variability in other layers is moderate. 2) On the slope, the distribution characteristics of soil moisture content were as follows: upslope <middleslope < downslope position. The differences of soil moisture between the upslope and downslope, midslope and downslope were significant. 3) The temporal stability analysis of the soil moisture showed that there is high stability between August and September of the soil moisture of the $0-50 \mathrm{~cm}$ and the correlation is extremely significant, while the soil moisture content of 50-100 cm range has a significant correlation between May and June. 4) The time stability of soil moisture in the middle slope position is the highest, followed by the upslope position, and the time stability in the downslope position is the lowest. 5) The best time stability point in the study area is the M3 point of the middle slope.
\end{abstract}

\section{Introduction}

Heterogeneity of soil moisture of spatial distribution and its stability with time is an important content of studying soil water variability. It is of great significance in analyzing and simulating soil solute transport, material transport, hydrological process, improving regional ecological environment, optimizing agricultural production mode, etc[1].

In recent years, the research of time stability of soil moisture has attracted the attention of many scholars [24]. The time stability of soil moisture has been successfully researched in many regions and different soil types [5-8]. Wang et al. (2009) studied soil water content in the Sichuan Basin, which provided a scientific basis for local agricultural management [9]; Zhang et al. (2017) analyzed the soil moisture of $0-2 \mathrm{~m}$ in the oasis desert transition zone [10]; Zhu et al. (2017) studied the surface soil moisture in alpine meadow ecosyste. In the the Loess Plateau area, the research on soil water mainly focuses on the dynamic change and distribution characteristics of soil moisture, and the in-depth research on the time stability of soil moisture is relatively lacking [5].

The Loess Plateau in China is a semi-arid ecologically fragile area, with the major landform of gully small watershed, accounting for $50 \% \sim 60 \%$ of the total area of the region [11]. Soil water is the primary limiting factor for plant growth, ecological restoration in the region, its strong spatiotemporal variability significantly affects the rational allocation of regional vegetation and the effective use of soil moisture [12]. Due to the lack of a correct assessment of the time stability of soil moisture in the gully basin, unreasonable vegetation selection and planting density in the long-term afforestation process led to the prominent problem of soil drying in forest land [13-14]. However, since 2013, the state has carried out volume gully management projects in the Loess Plateau. By the end of 2015, a total of $14000 \mathrm{hm}^{2}$ of gully regulation has been completed in Yan'an City [15-16]. The excavation and filling works in the process of gully regulation will change the terrain and vegetation coverage, and have a great effect on the hydrological process and the spatial-temporal distribution of water resources in the project implementation area [17-18], and then affect the spatial-temporal distribution of soil water on the slope. Therefore, studying the time stability of soil moisture of gully regulation can provide important support for ecological construction and restoration of the arid and semi-arid Loess Plateau [19-20].

In this study, we selected a typical gully small watershed in the Loess Plateau, and used Trime-TDR to 
monitor the soil moisture under different slope positions, and analyzed the time stability of soil water in this area, so as to provide a reference for local ecological reconstruction and gully comprehensive management.

\section{Material and Methods}

\subsection{Overview of Research Area}

The research area is located in Jiulongquangou watershed which is a typical watershed in Yan'an City, the Loss Plateau, China with geographic coordinates between $36^{\circ} 14^{\prime} 40^{\prime \prime} \mathrm{N}-36^{\circ} 19^{\prime} 25^{\prime \prime} \mathrm{N}, 109^{\circ} 35^{\prime}$ $50^{\prime \prime}$ E- $109^{\circ} 39^{\prime} 50^{\prime \prime}$ E, belonging to Hilly and Gully Area. The long-term erosion and undercutting of regional gullies make the slope active in gravity erosion, prone to collapse and landslide, and the gully surface is relatively gentle. The gully in the basin is $9.8 \mathrm{~km}$ long from the south to the north, and The altitude difference in the channel is $73 \mathrm{~m}$, and the average gradient is less than $1 \%$. The width of the valley ranges from $250 \mathrm{~m}$ to $500 \mathrm{~m}$. It belongs to temperate monsoon climate zone, cold and dry in winter, with less precipitation; hot and rainy in summer, with concentrated rainfall. The annual average temperature is $9{ }^{\circ} \mathrm{C}$, and the annual average frost free period is 179 days. The rainfall distribution is very uneven, change largely with time, and the utilization rate of water resources is low. The annual average precipitation is $573 \mathrm{~mm}$. The soil in the area is mainly yellow and brown soil. The vegetation is mainly shrub grassland and forest land, including Robinia pseudoacacia, conifer, etc.

\subsection{Sample Point and Test Method}

In this paper, a typical slope in Jiulongquangou watershed is selected as the experimental area. The direction of the mountain is north-south, and the direction of the slope in the experimental area is West semi sunny, with a slope of $15^{\circ}$. On the slope surface, 4 monitoring positions, i.e. upper slope position (U1, U2, U3, U4), middle slope position (M1, M2, M3, M4) and lower slope position (L1, L2, L3, L4), are selected respectively, with a total of 12 monitoring points for soil moisture location observation. The surface vegetation is all natural secondary shrubbery and grassland. Soil moisture monitoring is using TRIMEPICO TDR portable soil moisture meterbased on the time domain reflectometry (TDR). The observation depth is $0-100 \mathrm{~cm}$, and the soil moisture content is measured every $10 \mathrm{~cm}$. Four soil moisture measurements are conducted from May to September, 2017, with repeated 3 times.

\subsection{Analytical Methods}

\subsubsection{Coefficient of Variation}

The size of variability, can be reflected by the size of CV. The specific calculation formula is:

$$
C V=\frac{s}{m}
$$

Where, $\mathrm{m}$ is the average value of the sample;

$\mathrm{s}$ is the standard deviation. According to the degree of variation;

\subsubsection{Rank Correlation Coefficient}

Spearman rank correlation coefficient method is used for analysing the time stability of soil moisture, which reflects the similarity of observation samples in spatial model under different observation time. The formula of rank correlation coefficient $r_{s}$ can be calculated as follows:

$$
r_{s}=1-\frac{6 \sum_{i=1}^{N}\left(R_{i j}-R_{i j}\right)^{2}}{N\left(N^{2}-1\right)}
$$

In the formula, $R_{i j}$ is the rank level of the soil observation data at observation point $\mathrm{i}$ in time $\mathrm{j}$;

Rij' is the rank level of the observed data of soil moisture of observation point $i$ in time $j$ ';

$\mathrm{N}$ is the number of the observed sample samples of soil moisture.

The closer the $r_{s}$ is to 1 , the more similar the spatial distribution of soil water in time, that is, the stronger the temporal stability of soil water in the research.

\subsubsection{Determination Method of The Best Representative Monitoring Point of Time Stability}

The time stability index - Its to determine the time stability monitoring point, the formula is:

$$
I_{t s}=\sqrt{\delta_{i}^{2}+\sigma\left(\delta_{i}\right)^{2}}
$$

The smaller the time stability index is, the stronger the time stability is, and the more representative the soil moisture content is. Generally speaking, the point with time stability index lower than $10 \%$ can be probably regarded as the representative measurement point in time stability, and the point with the lowest value is the best representative measurement point of time stability.

\section{Results and Analysis}

\subsection{Change of Soil Moisture Content in Different Depths}

Figure 1 shows the average water content, standard deviation and variation coefficient of each monitoring point at different depths between May and September. It can be seen intuitively that the coefficient of variation of soil water content fluctuates greatly in different depths, with large amplitude, while the standard deviation and average value remain relatively stable. The average 
value of soil moisture water shows an increased trend with the increase of soil depth, and the range was $10.25 \% \sim 12.96 \%$. The variation coefficient of soil water increases, decreases and then increases with increasing of depth. The variation coefficient is $6.76 \%$, which is the smallest at about $70 \mathrm{~cm}$ from the surface. The variation coefficient is weak. The variation coefficient of soil water content in other layers is medium, while the variation coefficient is the largest at $20-40 \mathrm{~cm}$, which is greater than $20 \%$, and the overall variation range is $6.76 \%-22.57 \%$, which is the same as the study in Northwest China by Zhang et al. (2013). The standard deviation is less than $5 \%$, which indicates that the change of soil moisture water of time is relatively small at the same depth.

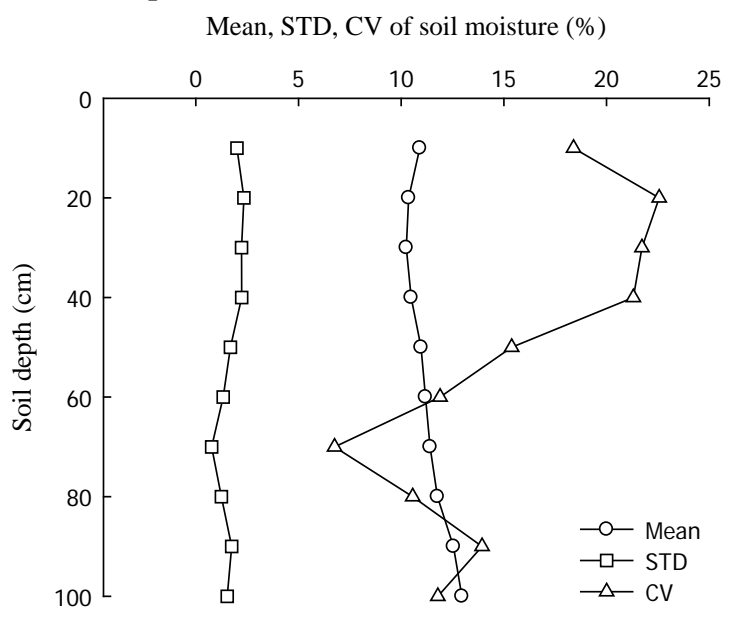

Fig.1. Mean value, standard deviation and coefficient of variation of soil water from May to September at different depths

Figure 2 reflects the correlation between the average value of soil water and the standard deviation. It is found by linear fitting by segmentation that when the average value of soil water content is below $11.4 \%$, it has a very significant linear correlation with the standard deviation ( $\mathrm{p}<0.001$ ), representing that when soil water in the research area is relatively small, the variability gradually decreases with increasing of soil water; contemporary, when soil water is greater than $11.4 \%$, the standard deviation increases with increasing of soil moisture content Trend, but its linear correlation is not significant. It shows that the relationship between the average soil water and its variability in research area is related to size of soil moisture content, which is mainly due to the influence of regional soil properties, climatic conditions, vegetation cover and other factors, and may also be related to the scale and Test methods and other factors.

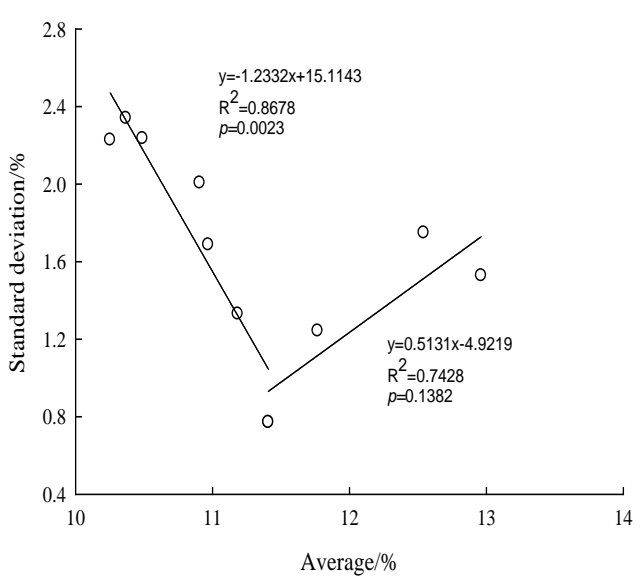

Fig.2. Relationship between average and standard deviation of soil water

\subsection{Time Stability of Soil Moisture in Different Depths}

This method is used to analyze time stability of soil water content. The Spearman rank correlation coefficient of $0-50 \mathrm{~cm}$ and $50-100 \mathrm{~cm}$ soil moisture is shown in Table 1. The table 1 reflects that during the observation period from May to September, the correlation of soil water content of $0-50 \mathrm{~cm}$ soil layer between each time is greater than that of $50-100 \mathrm{~cm}$ soil layer, which is different from the conclusion that the time stability obtained from most of research results increases with increasing of soil depth. Through further analysis of the correlation coefficient of Spearman rank of $0-50 \mathrm{~cm}$ soil moisture content, it showed that the correlation between the soil water content of May 13 and other monitoring time was not relevant ( $p>0.05$ ), while the soil moisture of June, August and September had a high stability, the correlation number range was 0.652-0.754, the correlation was significant ( $\mathrm{p}<0.01$ ); However, the soil moisture content in the range of $50-100 \mathrm{~cm}$ only has a significant correlation between May and June, and the correlation coefficient is 0.661 .

Table 1. Spearman rank correlation coefficient matrix of soil moisture from 0 to $100 \mathrm{~cm}$

\begin{tabular}{|c|c|c|c|c|c|}
\hline Depth & Date & $5-13$ & $6-11$ & $8-23$ & $9-28$ \\
\hline \multirow{4}{*}{$\begin{array}{c}0-50 \\
\mathrm{~cm}\end{array}$} & $5-13$ & 1 & 0.429 & 0.209 & 0.438 \\
\hline & $6-11$ & & 1 & $0.652 * *$ & $0.754 * *$ \\
\hline & $8-23$ & & & 1 & $0.721 * *$ \\
\hline & $9-28$ & & & & 1 \\
\hline \multirow{4}{*}{$\begin{array}{l}50- \\
100 \\
\mathrm{~cm}\end{array}$} & $5-13$ & 1 & $0.661^{* *}$ & -0.329 & 0.014 \\
\hline & $6-11$ & & 1 & -0.211 & $0.564 *$ \\
\hline & $8-23$ & & & 1 & 0.421 \\
\hline & $9-28$ & & & & 1 \\
\hline
\end{tabular}


correlation coefficient is significant at the level of $\mathrm{p}<$ 0.01 .

\subsection{Time Stability of Soil Moisture}

See Table 2 for Spearman rank correlation coefficient of soil moisture under different slope positions. The table 2 showed that during May August, the rank correlation coefficient of soil water content made a difference from different slopes. The range of the rank correlation coefficient of the upper slope is $0.164 \sim 0.879$, the average value is 0.471 , the rank correlation coefficient at middle slope is $0.394 \sim 0.745$, the average value is 0.626 , the rank correlation coefficient at lower slope is $-0.754 \sim 0.744$, the average value is -0.147 . On the whole, the time stability of soil moisture at middle slope is the highest, the next is upper slope, and the lower slope is the lowest.

Table 2. Spearman rank correlation coefficient matrix of moisture of different slope positions

\begin{tabular}{|c|c|c|c|c|c|}
\hline Slope position & Date & $\mathbf{5 - 1 3}$ & $\mathbf{6 - 1 1}$ & $\mathbf{8 - 2 3}$ & $\mathbf{9 - 2 8}$ \\
\hline \multirow{4}{*}{ Upper slope } & $5-13$ & 1 & 0.345 & 0.164 & 0.261 \\
\cline { 2 - 6 } & $6-11$ & & 1 & 0.600 & $0.879^{* *}$ \\
\cline { 2 - 6 } & $8-23$ & & & 1 & 0.576 \\
\cline { 2 - 6 } & $9-28$ & & & & 1 \\
\hline \multirow{5}{*}{ Middle slope } & $5-13$ & 1 & 0.527 & $0.685^{*}$ & 0.394 \\
\cline { 2 - 6 } & $6-11$ & & 1 & $0.745^{*}$ & $0.745^{*}$ \\
\cline { 2 - 6 } & $8-23$ & & & 1 & $0.661^{*}$ \\
\cline { 2 - 6 } & $9-28$ & & & & 1 \\
\hline \multirow{5}{*}{ Lower slope } & $5-13$ & 1 & 0.236 & $-0.754^{*}$ & -0.535 \\
\cline { 2 - 6 } & $6-11$ & & 1 & -0.280 & -0.292 \\
\cline { 2 - 6 } & $8-23$ & & & 1 & $0.744^{*}$ \\
\cline { 2 - 6 } & $9-28$ & & & & 1 \\
\hline
\end{tabular}

Note: * means the correlation coefficient is significant at the level of $\mathrm{p}<0.05$, ** means the correlation coefficient is significant at the level of $\mathrm{p}<$ 0.01 .

\subsection{Analysis of Time Stability Point}

The time stability index is calculated from the average value of the relative deviation and the standard deviation of the relative deviation, which is a comprehensive indicator. The smaller its value is, the stronger the time stability of the soil moisture content is. Figure 3 is a sequence diagram of the time stability index from small to large. It can be seen from the diagram that there are four monitoring points of time stability index of soil layer lower than $10 \%$, all of which are located in the middle slope position, the smallest of which is No. M2 monitoring points, with a value of $4.1 \%$. The index values of monitoring points at upper slope and the lower slope are all greater than $10 \%$.

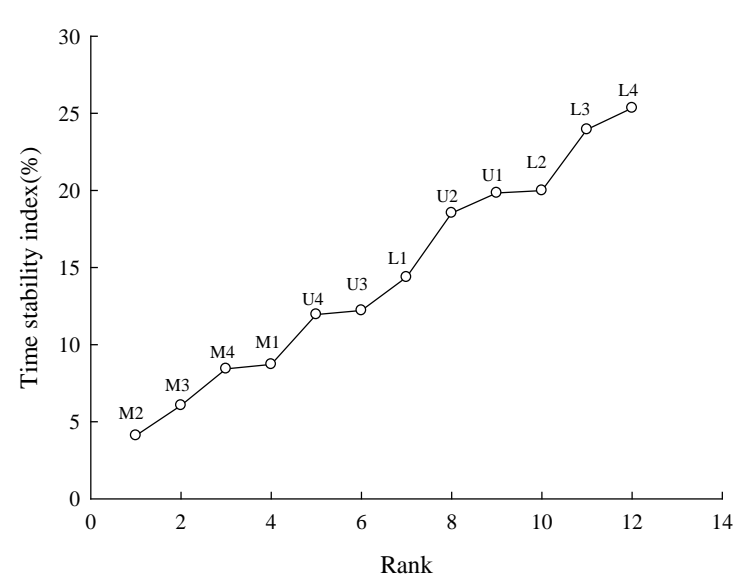

Fig. 3. Ranked temporal stability index of soil moisture

\section{Conclusions}

From May to September, 2017, the analysis of soil moisture at different slope positions and depths reflected that the mean value of soil moisture increasing with increasing of depth. The coefficient of variation of soil water increased - decreased - increased with increasing of depth, with the smallest variation at about $70 \mathrm{~cm}$ from the surface, being weak variability, The variability of soil water in other layers was moderate. At different slope positions in the watershed, the soil water content behaved the trend of upper slope water content $<$ middle slope position water content $<$ lower slope position water content, and the difference of moisture between lower slope and upper slope, lower slope and middle slope was significant. The variation characteristics of soil moisture content in different slope positions were all of medium variability.

By the study of Spearman's rank correlation coefficient for time stability of soil moisture we found that the correlation between the soil moisture content of $0-50 \mathrm{~cm}$ soil layer on May 13 and other monitoring time was not very relevant, while the soil moisture content of this layer between June, August and September had a high stability and a significant correlation $(\mathrm{p}<0.01)$; while the soil moisture content of $50-100 \mathrm{~cm}$ soil layer only had a higher correlation between May and June Significant correlation. The time stability of soil water at middle slope is the highest, then was the upper slope, and the lower slope is the lowest.

The best time stability point in the study area is M3 point in middle slope. The error between this point and the measured average value in the study area is small, which is the best representative time stability point of $0-100 \mathrm{~cm}$ soil layer.

Acknowledgements. This study was funded by National Natural Science Foundation of China (Grant No.51679188, 51979221).

\section{References}


1. D. G. Williams. Ecohydrology of water-controlled ecosystems: soil moisture and plant dynamics. - Eos Transactions American Geophysical Union, 86(38): 344-344 (2005)

2. Y. R. Bai, M. A. Shao. Temporal stability of soil water storage on slope in rain-fed region of Loess Plateau. - Transactions of the Chinese Society of Agricultural Engineering, 27(7):45-50 (2011)

3. W. Hu, M. A. Shao, Q. Wang. Scale-dependency of spatial variability of soil moisture on a degraded slope-land on the Loess Plateau.-Transactions of the Chinese Society of Agricultural Engineerin 21(8): 11-16 (2005)

4. S. Ersahin, A. R. Brohi. Spatial variation of soil water content in topsoil and subsoil of a typic ustifluvent.- Agricultural Water Management 83(1): 79-86 (2005)

5. X. C. Zhu, M. A. Shao, J. T. Zhu, J. Y. Zhang. Temporal stability of surface soil moisture in alpine meadow ecosystem on Northern Tibetan Plateau. - Transactions of the Chinese Society for Agricultural Machinery 48(8):212-218 (2017)

6. K. Vanderlinden, H. Vereecken, H. Hardelauf, M. Herbst, G. Martínez, M. H. Cosh, Y. A. Pachepsky. Temporal stability of soil water contents: areview of data and analyses.-Vadose Zone Journal 11(4):280288 (2012)

7. Y. X. Pan, X. P. Wang, Y. G. Su, X. J. Li, Y. H. Gao. Temporal stability of surface soil moisture in artificially revegetated desert area.- Journal of Desert Research 29(1): 81-86 (2009)

8. X. G. Xing, W. G. Zhao. X. Y. Ma, W. Zhao, W. J. Shi. Temporal stability of soil salinity in root zone of cotton under drip irrigation with plastic mulch. - Transactions of the Chinese Society for Agricultural Machiner 46(07):146-153 (2015)

9. G. G. Wang, C. F. Wei, J. K. Lv, W. H. Zhang. Spatial variation and its temporal stability of soil water in hilly area of Sichuan Basin.-Journal of Mountain Science 27(2):211-216 (2009)

10. S. P. Zhang, M. A. Shao. D. F. Li. Spatial distribution and temporal stability of soil water storage in an oasis-desert ecotone.- Chinese Journal of Applied Ecology, 28(8):2509-2516 (2017)

11. K. L. Tang. Soil and water conservation in China. - Science Press, Beijing (2004)

12. X. Y. Li, Z. H. Duan, X. H. Chen. Distribution of soil moisture under different planted shrubs on the West Loess Plateau.- Arid Zone Research 31(1):3843 (2014)

13. Z. Jin, L. Guo, Y. Q. Wang, Y. L. Yu, H. Lin, Y. P. Chen, G. C. Chu, J. Zhang, N. P. Zhang. Valley reshaping and damming induce water table rise and soil salinization on the Chinese Loess Plateau. Geoderma 339: 115-125 (2019)

14. M. A. Shao, Q. J. Wang, M. B. Huang. Soil physics.- Higher Education Press, Beijing (2006)
15. Y. S. Liu, Y. J. Guo, Y. R. Li, Y. H. Li. GIS-based effect assessment of soil erosion before and after Gully Land Consolidation: acase study of Wangjiagou Project Region, Loess Plateau. - Chinese Geographical Science 25(2): 137146 (2015)

16. Y. S. Liu, Y. H. Li. Environment: China's land creation project stands firm.-Nature 511(7510):410 (2014)

17. X. X. Yin, L. W. Chen, J. D. He, X. Q. Feng, W. Zeng. Characteristics of groundwater flow field after land creation engineering in the Hilly and Gully Area of the Loess Plateau. - Arabian Journal of Geosciences 9(14):646 (2016)

18. P. C. Sun, J. E. Gao, S. Q. Han, Y. Yin, M. F. Zhou, J. Q. Han. Simulation study on the effects of typical Gully Land Consolidation on runoff-sedimentnitrogen emissions in the Loess Hilly-gully Region. - Journal of Agro-Environment Science 36(6):1177-1185 (2017)

19. B. J. Fu, Z. J. Yang, Y. L. Wang, P. W. Zhang. Mathematical model of soil water spatial distribution on Loess Hilly Land.-Science in China( Series D) 31 （3） : 185-191 (2001)

20. Y. Q. Wang, M. A. Shao, Z. P. Liu. Spatial variability of soil moisture at aregional scale in the Loess Plateau. - Advances in Water Science, 23(3):310-316 (2012) 